NASA/TM-2002-:11500

\title{
Aeronautical Communications Research and Development Needs for Future Air Traffic Management Applications
}

Robert J. Kerczewski

Glenn Research Center, Cleveland, Ohio 
Since its founding, NASA has been dedicated to the advancement of aeronautics and space science. The NASA Scientific and Technical Information (STI) Program Office plays a key part in helping NASA maintain this important role.

The NASA STI Program Office is operated by Langley Research Center, the Lead Center for NASA's scientific and technical information. The NASA STI Program Office provides access to the NASA STI Database, the largest collection of aeronautical and space science STI in the world. The Program Office is also NASA's institutional mechanism for disseminating the results of its research and development activities. These results are published by NASA in the NASA STI Report Series, which includes the following report types:

- TECHNICAL PUBLICATION. Reports of completed research or a major significant phase of research that present the results of NASA programs and include extensive data or theoretical analysis. Includes compilations of significant scientific and technical data and information deemed to be of continuing reference value. NASA's counterpart of peerreviewed formal professional papers but has less stringent limitations on manuscript length and extent of graphic presentations.

- TECHNICAL MEMORANDUM. Scientific and technical findings that are preliminary or of specialized interest, e.g., quick release reports, working papers, and bibliographies that contain minimal annotation. Does not contain extensive analysis.

- CONTRACTOR REPORT. Scientific and technical findings by NASA-sponsored contractors and grantees.
- CONFERENCE PUBLICATION. Collected papers from scientific and technical conferences, symposia, seminars, or other meetings sponsored or cosponsored by NASA.

- SPECIAL PUBLICATION. Scientific, technical, or historical information from NASA programs, projects, and missions, often concerned with subjects having substantial public interest.

- TECHNICAL TRANSLATION. Englishlanguage translations of foreign scientific and technical material pertinent to NASA's mission.

Specialized services that complement the STI Program Office's diverse offerings include creating custom thesauri, building customized data bases, organizing and publishing research results ... even providing videos.

For more information about the NASA STI Program Office, see the following:

- Access the NASA STI Program Home Page at http://www.sti.nasa.gov

- E-mail your question via the Internet to help@sti.nasa.gov

- Fax your question to the NASA Access Help Desk at 301-621-0134

- Telephone the NASA Access Help Desk at 301-621-0390

- Write to: NASA Access Help Desk NASA Center for AeroSpace Information 7121 Standard Drive Hanover, MD 21076 
NASA/TM-2002-2.11500

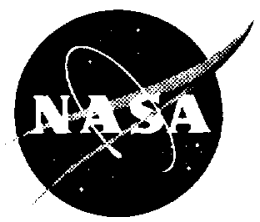

\section{Aeronautical Communications Research and Development Needs for Future Air Traffic Management Applications}

Robert J. Kerczewski

Glenn Research Center, (leveland, Ohio

Prepared for the

2002 Aerospace Conference

sponsored by the Institute of Electrical and Electronics Engineers

Big Sky, Montana, March 9-16, 2002

National Aeronautics an 1

Space Administration

Glenn Research Center 


\section{Available from}

NASA Center for Aerospace Information

7121 Standard Drive

Hanover, MD 21076
National Technical Information Service 5285 Port Royal Road Springfield, VA 22100

Available electronically at http://gltrs.grc.nasa.gov/GLTRS 


\title{
Aeronautical Conmunications Research and Development Needs for Future Air Traffic Management Applications
}

\author{
Robert J. Kerczewski \\ National Acronautics and Space Administration \\ Glenn Research Center \\ Cleveland, Ohio 44135
}

Abstract-Continuing growth in $\mathrm{r}$ :gional and global air travel has resulted in increasing traftic congestion in the air and on the ground. In spite of occasional temporary downturns due to economic reces ions and catastrophic events, average growth rates of ail travel have remained high since the 1960s. The resulting congestion, which constrains expansion of the air transportation industry, inflicts schedule delays and deceases overall system efficiency, creating a pressing nied to develop more efficient methods of air traffic management (ATM). New ATM techniques, procedures, airspa:e automation methods and decision support tools are seing researched and developed for deployment in time frames stretching from the next few years to the year 2020 and beyond. As these methods become more advanced and increase in complexity, the requirements for information generation, sharing and transfer among the relevant entitie; in the ATM system increase dramatically. However, current aeronautical communications systems will be inadequate to meet the future information transfer demands created by these advanced ATM systems. Therefore, the NASA Glenn Research Center is undertaking research programs to develop communications methods and key technologies that can meet these future requirements. As part of this process, studies, workshops, testing and experimentation, and research and analysis have established a number of research and technology development needs. The purpose of this paper is to outline the critical research and technology needs that have been identified in these activities, and explain how these needs have been determined.

\section{INTRODUCTICN}

As the aviation industry has grown during the nearly 100 years of its existence, air traffic control has evolved to deal with the constantly increasing traftic volume. Air traffic control today depends primarily on human air traffic controllers. Such measures as airspace sectorization, airspace structure, procedures and flow restrictions have been employed to prevent traffic levels from exceeding the human capability of the controllers'. But these methods ultimately constrain the total system throughput, with the result that system inefficiencies increase as traffic levels increase and any perturbation to the system can result in schedule upsets affecting the entire system. Even with total air traffic volume decreasing significantly immediately following the terrorist attacks of 11 September, 2001, the air traffic control system faced congestion during peak midday times equal to that before 11 September.

Recent efforts within the aviation community aim to develop a more flexible system to increase capacity and reduce inefficiencies by allowing users more freedom in attaining their operational objectives. Concepts such as "free flight" are being developed and implemented. NASA researchers, under the Advanced Air Transportation Technologies (AATT) Project ${ }^{2}$ are developing key decision support tools and automation methodologies to enable free flight concepts. In AATT, NASA is also researching more advanced, far-reaching ATM concepts known as Distributed Air/Ground Traffic management (DAG-TM). Free flight and DAG-TM are further described below.

A challenge for those developing and implementing advanced air traffic management tools and methods is the increased amount of information required. For example, DAG-TM concepts for enabling more autonomous en-route aircraft operations may require the collection and distribution of constantly updated position, speed and intent information for each aircraft, the "negotiation" of trajectories for conflict avoidance among two or more aircrafi, the coordination of trajectory changes with airline operations centers and airports, and a number of other transactions requiring significant exchanges of information that do not take place in today's ATM system. Many of these requirements were unanticipated when current and near-term future aeronautical communications links were specified. Therefore, it is anticipated that additional aeronautical communications capabilities will be required. Determining the future communications requirements and developing optimum architectures and technologies to meet those requirements is the goal of the aeronautical 
communications research efforts at the NASA Glenn Research Center. The following sections of this paper describe the approach being taken to assess communications system requirements and develop and validate appropriate aeronautical communication system architectures, and key research and development activities which have been identified as needed to bring about the next-generation aeronautical communications systems.

\section{FREE FLIGHT}

The prevailing concept for enabling higher capacity, more efficient air transportation systems is called free flight. Free flight is defined as "...a safe and efficient flight operating capability under instrument flight rules (IFR) in which operators have the freedom to select their path and speed in real time. Air traffic restrictions are only imposed to ensure separation, to prevent unauthorized flight through Special Use Airspace (SUA), and to ensure safety of flight. Restrictions are limited in extent and duration to correct the identified problem. Any activity which removes restrictions represents a move toward free flight. ${ }^{3}$

Free flight is intended to allow users or fleets of aircraft to optimize their use of airspace to meet their specific objectives. But there will always remain an air traffic management element to maintain flight safety. In addition, the airspace in the terminal areas will require significant control to maintain safety of arriving and departing aircraft. The level to which aircraft can operate autonomously is an area of significant debate and on-going research.

In the United States, the Federal Aviation Administration is implementing a free flight program within the National Airspace System (NAS) ${ }^{4}$. The Free Flight Phase I Program was established in 1998 and is intended to achieve, by 2002 , the implementation of five decision support tools intended as the first steps to a future free flight environment. The five decision support tools are:

1. Collaborative Decision Making (CDM) provides airline operations centers and the FAA with real-time NAS status information to improve airspace management. CDM includes three components: Ground Delay Program Enhancements, which enable the FAA Air Traffic Control System Command Center and airline operations centers to share information on airline schedules, projected airport demand and capacity rates to optimize airline operations; Initial Collaborative Routing to allow traffic management coordinators to share real-time traffic flow information with airline operations centers to improve overall NAS operational efficiency; and NAS Status Information tool, which enables real-time sharing of information about the status of the NAS.
2. User Request Evaluation Tool allows air traffic controllers to evaluate requests by pilots wishing to change directions or altitude from their prescribed flight path in en-route airspace. Controllers can use URET to evaluate a trial flight plan by identifying potential aircraft-to-aircraft conflicts up to 20 minutes ahead.

3. CTAS, the Center TRACON (Terminal Radar Approach Control) Automation System, has an En Route tool and a Terminal tool. CTAS En Route assists controllers in developing arrival sequence plans for selected airports, helping controllers optimize traffic flow into the airport and efficiently use available nunways and surrounding airspace.

4. The CTAS Terminal tool assists controllers in optimizing traffic flow to touchdown, maximizing runway utilization and providing enhanced situational awareness at the TRACON.

5. Surface Movement Advisor (SMA) provides increased awareness of traffic flow into the airport, providing precise touchdown times to ramp control operators. This information enables the airlines to more efficiently manage ground operations.

The Free Flight Phase 2 Program will continue the introduction of new tools and initiatives currently in development and expand the coverage of tools implemented in Phase 1. Phase 2 is scheduled for 2003 to 2005.

\section{ADVANCED ATM CONCEPTS}

NASA researchers at the Ames and Langley Research Centers are now involved in research and development of Distributed Air/Ground Traffic Management (DAG-TM) concepts. DAG-TM is defined by a set of concept elements that describe advanced or "mature" free flight as defined by the RTCA Task Force $3^{3}$.

The DAG-TM concept was defined by the DAG-TM Team under NASA's AATT Project. Whereas much of the AATT Project is focused on the development of decision support tools that may be implemented in the FAA's Free Flight Phase 2 or later phases, the DAG-TM concepts represent more far term research to investigate and evaluate the feasibility of individual DAG-TM concept elements. If proven feasible, future projects will develop the concepts into implementable tools.

The fundamental characteristics of DAG-TM are defined as follows: "Distributed Air/Ground Traffic Management is a National Airspace System concept in which flight deck (FD) crews, air traffic service providers (ATSP), and aeronautical operational control (AOC) facilities use 
distributed decision-making to enable user preferences and increase system capacity, while meeting air traffic management requirements. DAG-TM will be accomplished with a human-centered operational paradigm enabled by procedural and technological innovations. The innovations include automation aids, information sharing, and Communication, Navigation and Surveillance (CNS)/ATM technologies."

Figur: 1 - Overview of DAG-TM Concept Elements

\begin{tabular}{|c|l|}
\hline $\begin{array}{c}\text { Concept } \\
\text { Element }\end{array}$ & \\
\hline 0 & Gate-to-Gate: \\
\hline 1 & Pre-Flight Planning: \\
\hline 2 & Surface Departure: \\
\hline 3 & Terminal Departure: \\
\hline 4 & Terminal Departure: \\
\hline 5 & $\begin{array}{l}\text { En Route: } \\
\text { (Departure, Cruise, } \\
\text { Arrival) }\end{array}$ \\
\hline 6 & $\begin{array}{l}\text { En Route: } \\
\text { (Departure, Cruise, } \\
\text { Arrival) }\end{array}$ \\
\hline 7 & $\begin{array}{l}\text { En Route: } \\
\text { (Departure, Cruise, } \\
\text { Arrival) }\end{array}$ \\
\hline 8 & $\begin{array}{l}\text { En Route/Terminal } \\
\text { Arrival: }\end{array}$ \\
\hline 9 & Terminal Arrival: \\
\hline 10 & Terminal Arrival: \\
\hline 11 & Terminal Arrival: \\
\hline 12 & Terminal Arrival: \\
\hline 13 & \begin{tabular}{l} 
Terminal Approach: \\
\hline 14
\end{tabular} \\
\hline & Surface Arrival: \\
\hline
\end{tabular}

Information Access/Exchange for Enhanced Decision Support

NAS-Constraint Considerations for Schedule/Flight Optimization

Intelligent Routing for Efficient Pushback times and Taxi

Free Maneuvering for User-preferred Departures

Trajectory Negotiation for User-preferred Departures

Free Maneuvering for:

(a) User-preferred separation assurance, and

(b) User-preferred local Traffic Flow Management conformance

Irajectory Negotiation for:

(c) User-preferred separation assurance, and

(d) User-preferred local TFM conformance

Collaboration for Mitigating Local TFM Constraints due to Weather, SUA and Complexity

Collaboration for User-preferred Arrival Metering

Free Maneuvering for Weather Aroidance

Trajectory Negotiation for Weather Avoidance

Self-Spacing for Merging and In-trail Separation

Trajectory Negotiation for Merging and In-trail Separation

Airborne CD\&R for Closely Spaced Approaches

Intelligent Routing for Efficient Active-Runway Crossings and Taxi
The DAG-TM operational concep is described by 15 concept elements (CE), which repesent a solution to a problem or inefficiency in the opcrations of the current NAS. They correspond in siquence to elements encountered in the progression of a 1ypical flight. Figure 1 is a summary of the DAG-TM concept elements.

Note that several adjacent pairs of ccncept elements address the same problem through different :olution strategies. For example CE 3 and CE 4 both address user-preferred departures, but CE 3 uses free mantuvering to accomplish the solution while CE 4 uses trajectory negotiation. CEs 5 and 6,9 and 10 , and 11 and 12 form similar pairs. In general, free maneuvering is a flight deck focused solution that allows each user to determine a preferred operation while maintaining responsibility for safety and separation assurance (conflict avoidance). Thıs may include direct "negotiation" with other users to determine methods of conflict avoidance. The ATSP provides oversight and can enter into a controlling mode when di:emed necessary.
Trajectory negotiation, on the other hand, is an ATSPcentered solution that requires users to negotiate trajectories with the ATSP. In this case the ATSP always maintains responsibility for safety and separation assurance. These two strategies are not necessarily mutually exclusive within the NAS. Either may be the preferred solution depending on variables such as airspace complexity and user equipage.

However, it is important to note that significant differences in communication requirements may occur between the two strategies. For example, free maneuvering may require more information exchange from aircraft to aircraft, while trajectory negotiation may require more information exchange between aircraft and ground facilities.

As part of the AATT Project DAG-TM research program, four of the 15 concept elements are being included in a full feasibility study. The concept elements chosen for study are CEs 5, 6, 7, and 11 . 


\section{DEVELOPMENT OF COMMUNICATIONS REQUIREMENTS AND ARCHITECTURES}

The previous discussion on potential communications requirements differences resulting from different free flight approaches to solving a NAS problem illustrates the difficulty in assessing aeronautical communications requirements for future ATM applications. The primary communications links being implemented over the next ten years for safety of flight communications, which includes air traffic management, are already in the final stages of development or early stages of deployment. Therefore, new communications architectures must be developed to meet requirements beyond the ten-year time frame. With many new air traffic management tools and methods in the early research stages, it is unknown which will end up being chosen for future implementation. Traffic loads can only be estimated, and many other unknown issues will impact aviation by the 2015 to 2020 timeframes being considered. The terrorist attacks of 11 September, 2001 combined with economic recession reduced air travel by 10 to $20 \%$ immediately following the event. History indicates that this will be a temporary deviation from the continuing increase in aviation traffic over the long term, but it remains to be seen when air traffic will return to pre-11 September levels. Hence, communications requirements cannot be derived with great accuracy.

But it is important to attempt to estimate future needs in order to perform useful research and technology development. NASA Glenn has therefore approached the development of future communications requirements and supporting communication system architectures from several fronts.

First, several requirements and architecture studies commissioned by NASA Glenn have been performed by a range of aviation industry and aeronautical communications experts. Second, simulation and modeling at NASA Glenn to characterize the performance of digital aeronautical communication links and eventually develop large scale communication system models. Third, the development of hardware-based system testbeds to measure real performance of aeronautical communication systems. Fourth, the first of an annual series of conferences and workshops on communications, navigation and surveillance for advanced future air transportation systems, in May, 2001 , provided of industry, government and academic input into future CNS requirements and research and technology needs.

Communications requirements and architecture studies have been completed to address several different issues. The first study, by Lockheed Martin Aeronautical Systems in $1998^{5}$, considered the potential use of satellite communications systems for future air traffic management applications and reached a number of useful conclusions regarding satellite communications links applied to air traffic management, potential benefits and technology needs.

A major study commissioned under the NASA AATT NRA Research Task Order contract was the Communications System Architecture Development for Air Traffic Management and Aviation Weather Information Study, performed by Science Applications International Corporation (SAIC), ARINC, TRW and Crown Consulting, completed in May $2000^{6}$. This study developed a complete set of current and future communications requirements through assessment of existing documents containing needs and requirements. The contractor team confronted the difficulty of reconciling many conflicting and overlapping needs and objectives contained in these documents, as well as estimating potential future requirements based on proposed operational concepts, air traffic management research objectives (such as DAG-TM) and many other inputs. This is the first known attempt to gather such a complete set of documented requirements. The study went on to develop potential communications system architectural solutions, including various communication links options and approaches based on communications capacity and functionality requirements. Figure 2 shows the overall functional architecture demonstrating the required data flow for a future communications system architecture and taking into account many systems, datalinks and programs currently in place or under development. The study broke down the overall system architecture into the various specific communications architectures required to fully specify the overall architecture. The final portion of the study compared current technologies in place or under development with technologies needed for implementing the future architecture to identify technology gaps that need to be addressed to enable such future systems.

A follow-on study by Computer Networks and Software, Inc., built upon the previous studies and refined the analysis of future communication needs to develop a set of specific research and technology gaps ${ }^{7}$. These gaps address a range of issues in both the near/mid term (next 10 years) and long term (beyond 10 years) time frames, and are listed as follows (not in prioritized order).

1. National Communications Traffic Loading Model

2. Commodotized Airspace Research

3. Frequency Use and Planning

4. Dynamic Frequency Assignment Process

5. RF Improved VHF Data Link Concept

6. CPDLC Latency in Terminal Area

7. Impact of CPDLC System Latency

8. Multiple Radio Equipage Mitigation

9. Co-site and Antenna Isolation

10. Datalink Transition Planning

11. Datalink Performance Test/Evaluation

12. Satellite Based Communication

13. Security/Vulnerability 


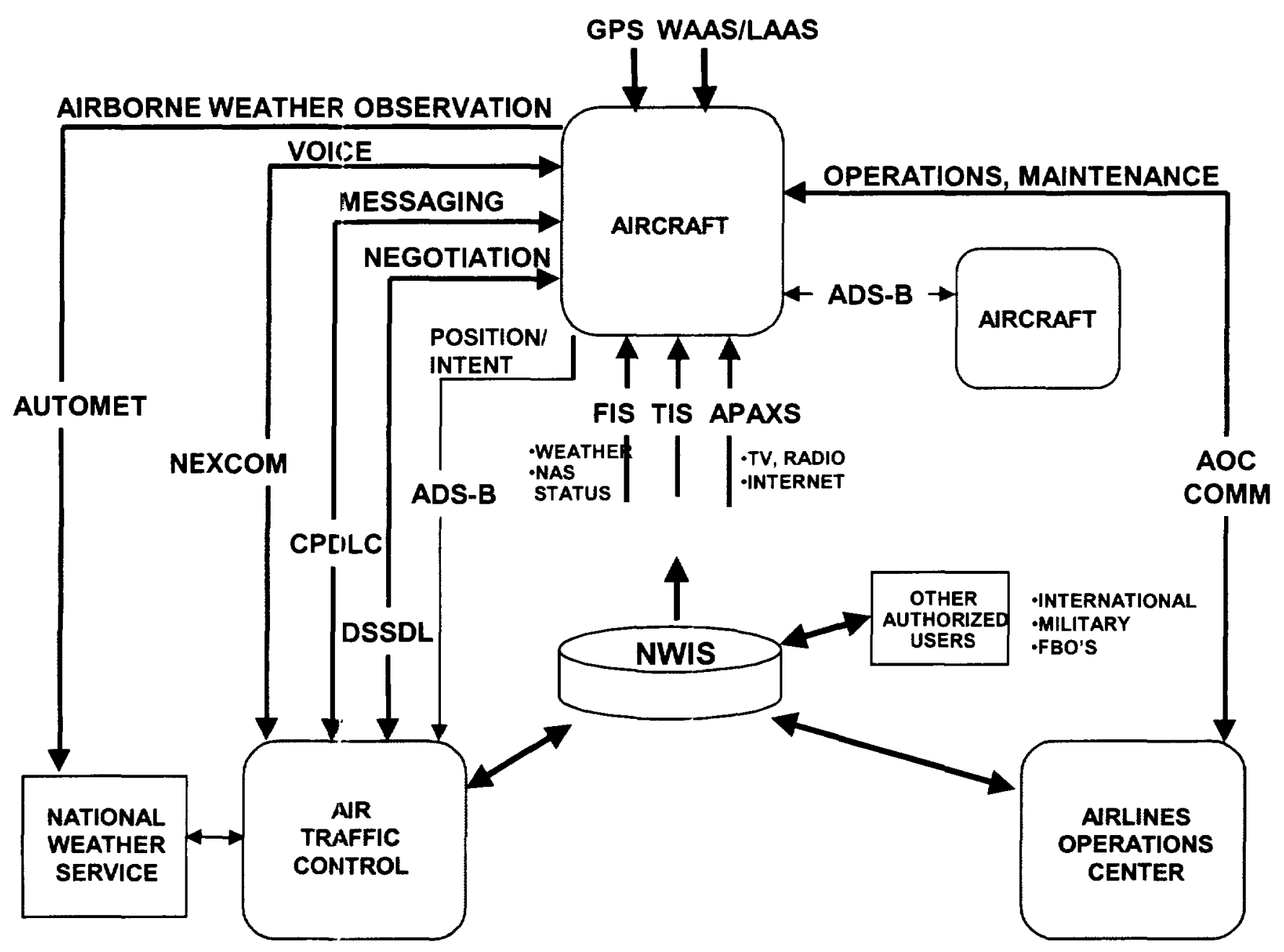

Fig.ure 2 - Functional aeronautical communication system architecture

14. Network Management

15. Use of COTS TCP/IP

16. Airborne Internet (air-to-iir network)

17. Low Cost End Systems for ( $j A$

18. COTS Wireless On-board

19. VDL- 3 Performance in Failure Modes

20. Human Factors Related to Use of Communications Datalinks

Detailed information on these technulogy gap issues can be found in [7].

The second area of effort in determining future aeronautical communications needs is simulation and modeling. NASA Glenn researchers are currently focusing on VHF Digital Link (VDL) Modes 2, 3, and 4, aeronautical communication satellite links, and navigation an 1 surveillance system performance for supporting future air traffic management concepts. OPNET network simulation software is being used to develop and exercise performance models of VDL-2 and VDL-3. The purpose is to acquire accurate performance models to determine such things as true data throughput capabilities, system performance degradation as a function of channel loading, and network performance. These results will lead to an understanding of the capabilities of such systems to support advanced future ATM automation tools, and can also lead to potential system improvements.

As an example of such efforts, recent successes in VDL-2 system performance modeling and simulation at NASA Glenn indicate potential improvements to the VDL-2 carrier sense multiple access format can achieve significant system improvements $^{8}$. In a simulation involving 111 VDL-2 
ground stations, 32 airports, and 1235 flying realistic flight trajectories. Controller Pilot Datalink Communications (CPDLC) messaging is modeled in this simulation. Latency, throughput and packet loss measurements in this simulation indicate significant system performance improvements are possible.

A long-term simulation and modeling goal is to combine the individual datalink models into a larger hybrid communication architecture simulation to evaluate various architectural approaches on a NAS-wide basis.

The third area of effort in determining future aeronautical communications needs involves the development of hardware-based testbeds. Two types of testbeds being developed for this purpose are mobile aeronautical terminals and laboratory-based testbeds.

An aeronautical satellite communications terminal has been developed to demonstrate and evaluate wideband satellite communications. The terminal is based upon $\mathrm{Ku}$-band phased array antennas developed by Boeing and is described in detail in [9]. The terminal has been developed for use in a ground mobile platform, enabling low-cost mobile testing of components, network concepts and applications. It can also be used in occasional flight tests, as has already been accomplished using NASA Dryden Flight Research Center's DC-8 experiment aircraft. These successful tests demonstrated several different network protocols, including Aeronautical Telecommunications Network (ATN) and IP, and a number of network applications over IP (e-mail, web browsing, voice-over-IP) and ATN (CPDLC). The addition of VDL-2 capabilities to the $\mathrm{Ku}$-band satellite communications terminal will enable testing of advanced hybrid network topologies.

Laboratory-based testbeds are now in development to enable the testing of VDL communication links. These testbeds will enable controlled testing of VDL link performance under realistic conditions obtained by simulating the VDL interactions of up to 160 aircraft combined with several real VDL links, which can include actual test aircraft or ground mobile vehicles. Such testing will enable accurate real world measurements of system performance under maximum loading conditions and enable hybrid network performance measurement, leading to an understanding of the real potential capacity of VDL datalinks.

The fourth area of effort in determining aeronautical communications requirements and identifying key research and technology needs is the Workshop on Integrated CNS for Future Advanced Air Transportation Systems, hosted by NASA Glenn May 1-3, $2001^{10}$. The first of an anticipated annual series of such workshops, it gathered 135 experts from aviation industry, academia, and government agencies to discuss current status in aeronautical CNS system implementation and near-term developments, and research and development efforts. The workshop also developed a statement of critical needs in research and technology development for CNS systems. See [10] for further details.

\section{AERONAUTICAL COMMUNICATIONS RESEARCH AND DEVELOPMENT NEEDS}

The efforts described above have led to the understanding of aeronautical communications research and technology development needs for ATM applications described next. Note that the refining and updating of these needs will be an on-going process as new information is gained through studies, modeling and simulation, and testing and experimentation. In addition, constant feedback from the aviation community will be solicited. Of course, the purpose of developing this needs list is to maximize the value of NASA's research efforts, as well as the research efforts of many other government, academic and private institutions, both in the US and internationally. It also serves to support program advocacy and coordination and collaboration efforts between institutions.

The results below summarize the current understanding of research and technology development needs. They are organized into two groups: the first involves near $/ \mathrm{mid}$ term needs covering the next ten years' needs, the second covers long term needs beyond ten years. For each of these groups, three categories of research and technology needs are listed: systems research and analysis, which includes requirements analyses, architecture development, simulation and modeling, and other research issues; component technology research and development, which deals with hardware component needs; and system/network technology research and development, covering testing, evaluation and demonstration of systems and networks, protocol and standards development, and system level concept and applications research.

\section{$\underline{\text { Near/Mid Term Needs }}$}

Systems Research and Analyses

Requirements Analysis:

1. Requirements analysis for terminal area communications.

2. Communications needs for smaller airports.

3. Integration and networking of communications, navigation and surveillance infrastructures.

4. CNS requirements for collaborative decision making and moving towards aircraft selfseparation and airspace automation.

5. Analysis of communications latency, handoff and related issues. 
System Analysis/Architecture Der clopment:

1. Development of modeling simulation capability and laboratory testbed facility to enable objective assessment of performance of planned digital datalinks.

2. Objective evaluations of pl nned digital datalinks, including VDL-2, 3 and 4.

3. Analysis/development of noves toward future "harmonization" of ATN and IPv6 network protocols.

4. Research and analysis of hybrid system architecture issues (aciommodating mixed equipage, datalink vs. non-ditalink airspace, etc.)

5. Human factors analysis of : nformation integration and presentation to human o serators.

Spectrum and Frequency Use Ress'arch:

1. Datalink, aeronautical spectrum allocation and spectrum protection/usage strategies.

Component Technology Research \& 1 Jevelopment

1. Antenna technologies, ircluding co-site and isolation issues.

2. On-board data distribution te chnologies.

3. Digital data network components.

4. Multi Mode Digital Radios - Software Reconfigurable Radios.

System/Network Technologv Researcn \& Development

1. Development/demonstration of mobile network technologies.

2. Development/demonstration of hybrid terrestrial/space commurication system and network technologies.

3. Enabling of initial insertion of satellite communications technologies within ten years.

4. International standards delclopment for inclusion of advanced CNS technologies.

5. Aeronautical/mobile protocol research and development.

\section{Long Term Needs}

\section{Systems Research and Analysis}

Requirements Analysis:

1. Long term national and lobal integrated CNS infrastructures.

2. Enabling of "quantum leap" in aeronautical system information flow.

3. Enabling of "Dynamic, nsar-real-time" aviation system-level collaboration.
4. Long-term performance and reliability requirements.

5. Security/vulnerability requirements.

System Analysis and Architecture Development:

1. Development of high-fidelity national/global CNS system/network modeling and simulation capability.

2. Development and validation of national/global integrated CNS infrastructure architecture.

3. Airborne Internet with "mobile within mobile" capability.

4. Enable implementation of "harmonized" ATN/IP network.

Spectrum and Frequency Use Research:

1. Methodologies for higher spectral efficiencies.

2. Enable dynamic frequency/bandwidth access.

3. Move from frequency channel paradigm to bandwidth allocation paradigm.

Component Technologv Research \& Development

1. Low cost COTS-based communications component technologies.

2. Component/subsystem reconfigurability - preplanned retrofit technologies.

System Nerw'ork Technology Research \& Development

1. Improved surveillance system technology for advanced airspace automation needs.

2. Enable full implementation of satellite communications "backbone".

3. High speed (ultra wideband) multi function datalinks.

4. Major advances in ground communications process/infrastructure to support collaboration on a global basis.

5. High situational awareness on the ground (including synthetic vision technologies).

Other Issues Not Included in the Above Categories:

1. Need for new certification paradigm to enable the rapid infusion of new technologies.

2. Research work on revolutionary "clean sheet" approach to a new integrated national/global CNS system by 2025 .

\section{CONCLUSIONS}

Continued growth in aviation can only be accommodated by developing and implementing new air traffic management techniques. Such techniques will require a "quantum leap" 
in aviation system information flow. To move information on a regional and global basis between aircraft, air traffic service providers, airline operations centers and various other components, major improvements of the aeronautical communications infrastructure will be necessary. This requires a robust research and technology development program.

In order to maximize the value of research and technology development resources and support the advocacy of research programs, it is necessary to understand well the research and technology development needs. The NASA Glenn Research Center has taken a broad-based approach to identifying those needs. This approach has been described in this paper. With the understanding that these requirements must be continuously refined and updated, the current understanding of critical research and technology development needs for aeronautical communications have been presented.

\section{REFERENCES}

[1] Concept Definition for Distributed Air-Ground Traffic Management (DAG-TM), http://www.asc.nasa.gov/aatt/dag.html.

[2] Advanced Air Transportation Technologies Project (AATT), http://www.asc.nasa.gov/aatt/.

[3] Final Report of RTCA Task Force 3: Free Flight Implementation. RTCA, Inc., Washington, D.C., October 26, 1995.

[4] Federal Aviation Administration: Free Flight, http://ffpl.faa.gov/about/about.asp.

[5] NASA Advanced Air Transportation Technologies (AATT) Program Free Flight Satellite Communication Study, Final Report, Lockheed Martin Aeronautical Systems, for NASA Glenn Research Center, August, 1998.
[6] Communications System Architecture Development for Air Traffic Management and Aviation Weather Information Dissemination, Science Applications International Corporation for NASA Glenn Research Center, Contract NAS2-98002, May, 2000.

[7] "CNS Gap Analysis", Computer Networks and Software, Inc., for NASA Glenn Research Center, March 2001.

[8] CSMA Versus Prioritized CSMA for Air-Traffic Control Improvement, D. Robinson, 2002 IEEE Aerospace Conference, Mar 2002.

[9] Satellite Communications for Aeronautics Applications - Technology Development and Demonstration. R. J. Kerczewski, D. J. Hoder, R. J. Zakrajsek, 2001 IEEE Aerospace Conference, March 2001.

[10] Workshop on Integrated CNS Technologies for Advanced Future Air Transportation Systems, http://spacecom.grc.nasa.gov/cnsworkshop/.

Robert $J$. Kerczew'ski has been involved with research and development of satellite communications systems and applications since for the Analex Corporation (1982-1986) and NASA (1986-present). He holds a BEE degree from Cleveland State University (1982) and an MSEE degree from Case

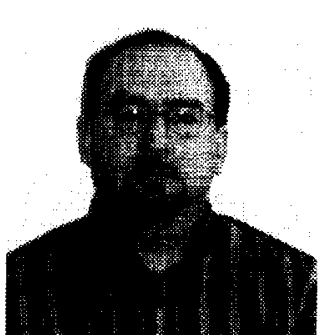
Western Reserve University (1987). He is currently the Project Manager for the Advanced Communications for Air Traffic Management element of NASA's Advanced Air Transportation Technologies (AATT) Project. 


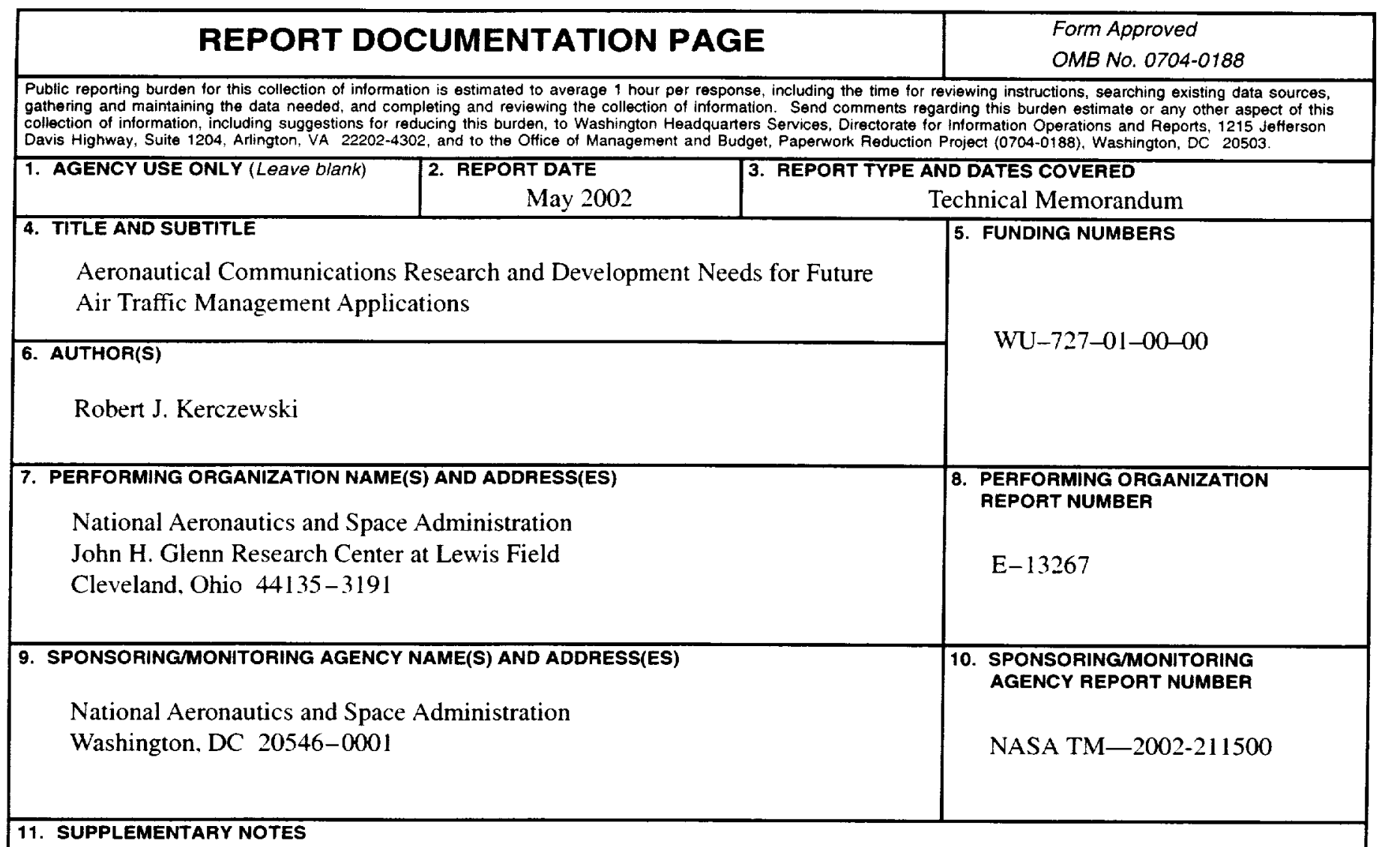

Prepared for the 2002 Aerospace Conference sponsored by the Institute of Electrical and Electronics Engineers, Big Sky, Montana, March 9-16, 2002. Responsible person, Robert J. Kerczewski, organization code 6160, 216-433-3434.

12a. DISTRIBUTION/AVAILABILITY STATEMENT 12b. DISTRIBUTION CODE

Unclassified - Unlimited

Subject Category: 04

Distribution: Nonstandard

Available electronically at http://gltrs.grc.nasa.gov/GLTRS

This publication is available from the NASA Center for AeroSpace Information. 301-621-0390.

13. ABSTRACT (Maximum 200 words)

Continuing growth in regional and global air travel has resulted in increasing traffic congestion in the air and on the ground. In spite of occasional temporary downturns due to economic recessions and catastrophic events, average growth rates of air travel have remained high since the 1960 s. The resulting congestion, which constrains expansion of the air transportation industry, inflicts schedule delays and decreases overall system efficiency, creating a pressing need to develop more efficient methods of air traffic management (ATM). New ATM techniques, procedures, airspace automation methods, and decision support tools are being researched and developed for deployment in time frames stretching from the next few years to the year 2020 and beyond. As these methods become more advanced and increase in complexity, the requirements for information generation, sharing and transfer among the relevant entities in the ATM system increase dramatically. However, current aeronautical communications systems will be inadequate to meet the future information transfer demands created by these advanced ATM systems. Therefore, the NASA Glenn Research Center is undertaking research programs to develop communications methods and key technologies that can meet these future requirements. As part of this process, studies, workshops, testing and experimentation, and research and analysis have established a number of research and technology development needs. The purpose of this paper is to outline the critical research and technology needs that have been identified in these activities, and explain how these needs have been determined.

\begin{tabular}{|c|c|c|}
\hline $\begin{array}{l}\text { 14. SUBJECT TERMS } \\
\text { Radio communication; } T \\
\text { Aircraft communication }\end{array}$ & communication; Satellite co & unication; \\
\hline $\begin{array}{l}\text { 17. SECURITY CLASSIFICATION } \\
\text { OF REPORT } \\
\text { Unclassified }\end{array}$ & $\begin{array}{l}\text { 18. SECURITY CLASSIFICATION } \\
\text { OF THIS PAGE } \\
\text { Unclassified }\end{array}$ & $\begin{array}{l}\text { 19. SECURITY CLASSIFICATION } \\
\text { OF ABSTRACT } \\
\text { Unclassified }\end{array}$ \\
\hline
\end{tabular}

NSN 7540-01-280-5500 